\title{
Estimating the Impact of Time-Invariant Variables on FDI with Fixed Effects
}

\author{
Davies, Ronald B.; Ionascu, Delia Simona; Kristjánsdóttir, Helga
}

Document Version

Final published version

Publication date:

2007

License

CC BY-NC-ND

Citation for published version (APA):

Davies, R. B., Ionascu, D. S., \& Kristjánsdóttir, H. (2007). Estimating the Impact of Time-Invariant Variables on FDI with Fixed Effects. Department of Economics. Copenhagen Business School. Working Paper / Department of Economics. Copenhagen Business School No. 2-2007

Link to publication in CBS Research Portal

\footnotetext{
General rights

Copyright and moral rights for the publications made accessible in the public portal are retained by the authors and/or other copyright owners and it is a condition of accessing publications that users recognise and abide by the legal requirements associated with these rights.

Take down policy

If you believe that this document breaches copyright please contact us (research.lib@cbs.dk) providing details, and we will remove access to the work immediately and investigate your claim.
}

Download date: 26. Apr. 2023 
Copenhagen

Business School

HANDELSHØJSKOLEN

\section{Department of Economics}

Copenhagen Business School

Working paper 2-2007

\section{ESTIMATING THE IMPACT OF TIME-INVARIANT VARIABLES ON FDI WITH FIXED EFFECTS}

Ronald B. Davies Delia Ionascu, Helga Kristjánsdóttir

$\overline{\text { Department of Economics -Porcelænshaven 16A, 1.fl. - DK-2000 Frederiksberg }}$ 


\title{
Estimating the Impact of Time-Invariant Variables on
}

\author{
FDI with Fixed Effects
}

\author{
Ronald B. Davies ${ }^{*}$, Delia Ionascu ${ }^{* *}$, and Helga Kristjánsdóttir ${ }^{* * *}$
}

\begin{abstract}
This paper applies the panel fixed effects with vector decomposition estimator to three FDI datasets to estimate the impact of time-invariant variables on FDI while including fixed effects. We find that the omission of fixed effects significantly biases several of these variables, especially those proxying for trade costs and culture. After including fixed effects, we find that many time-invariant variables indicate the importance of vertical FDI. We also find that by eliminating these biases, the differences across datasets largely disappear. Thus, controversies in the literature that are driven by differences in data sets may be resolved by using this estimation technique.
\end{abstract}

JEL Classification: F14, F23

Key Words: Foreign Direct Investment, Trade Costs, Culture

\footnotetext{
* Department of Economics, 435 PLC Building, 1285 University of Oregon, Eugene, OR 97405. Phone: (541) 346-4671. Fax: (541) 346-1243. Email: rdavies@uoregon.edu. This paper was written while supported by the Institute for International Integration Studies at Trinity College, Dublin. I graciously acknowledge their support.

** Department of Economics, Copenhagen Business School, Porcelænshaven 16A, 2000 Frederiksberg, Denmark; Phone: +45 38152605; Fax: +45 3815 2576; E-mail: di.eco@cbs.dk

*** Departments of Economics, Oddi við Sturlugötu, 101 Reykjavík, Iceland. Phone: +354 551-1718; Fax: +354 551-1718; E-mail: helgakr@hi.is. Research supported by the Icelandic Research Fund.
} 


\section{Introduction}

In the empirical literature on foreign direct investment (FDI), several variables have entered the standard canon of control variables. Some of these, such as GDP of the parent and host countries, vary over time. Others, such as distance between countries, do not. As a result, when using fixed effects to control for unobserved variation across countries, coefficients for these time-invariant variables cannot be estimated. ${ }^{1}$ Nevertheless, doing so is important because such variables proxy for trade costs and therefore yield insights into the motivation behind FDI. If FDI happens in order to gain access to consumers, higher trade costs are expected to increase FDI (horizontal FDI). ${ }^{2}$ Alternatively, if FDI takes place to create global production networks, higher trade costs decrease FDI (vertical FDI). ${ }^{3}$ Recently, however, Plümper and Troeger (forthcoming) have developed a three-stage estimation procedure that efficiently estimates the impact of time-invariant variables while also controlling for fixed effects. The primary goal of this paper is to apply this panel fixed effects with vector decomposition (XTFEVD) method to three commonly used FDI data sets. ${ }^{4}$ Importantly, we find that the coefficients on several commonly-used time-invariant variables change sign when doing so. After correcting for the biases caused by the omission of fixed effects, our estimates suggest the importance of vertical FDI. In addition, we find that using XTFEVD is useful in

\footnotetext{
${ }^{1}$ For example, as demonstrated by Baltagi, Egger, and Pfeffermayr (forthcoming) and Blonigen, Davies, Waddell, and Naughton (forthcoming) including fixed effects is typically sufficient to absorb any third country effects.

${ }^{2}$ Models in this vein include Markusen's (1984) seminal paper and recent innovations such as the export platform literature of Ekholm, Forslid, and Markusen (forthcoming), Bergstrand and Egger (forthcoming), and Yeaple (2003).

${ }^{3}$ Early work in this direction includes that of Helpman (1984). More recent contributions include Baltagi, Egger, and Pfaffermayr (forthcoming). The knowledge capital model, discussed in detail by Markusen (2002), incorporates aspects of both vertical and horizontal FDI.

${ }^{4}$ As detailed below, we use bilateral stock and sales data involving the US, bilateral stock data involving an OECD country, and inbound and outbound flows from the World Bank.
} 
eliminating many of the differences in the coefficients found across data sets. This suggests that the presence of unobserved country heterogeneity and differences in the extent of this problem across data sets may be behind many of the controversies in the empirical literature on FDI (see Blonigen, 2005, for a recent survey of these debates). Thus, XTFEVD is a useful tool in resolving these problems.

Our second contribution is to use information on culture to ascertain the degree to which the cultures of the parent and host countries affect investment patterns. There is a growing body of theory looking at the impact of culture (which is related to networks both in production and consumption) and international trade issues (see Janeba, forthcoming, for a recent review). Using the cultural indicators developed by Hofstede (1980) and Hofstede and Bond (1988), we find that culture is a significant predictor of FDI. Since these measures do not vary over time, XTFEVD is again useful for removing the biases caused by unobserved heterogeneity across countries. In particular, our estimates suggest that it is more the cultural attributes of the parent and the host separately that matter rather than the differences between them. Specifically, we find that more FDI comes from and goes to countries built around masculine values (e.g. competitiveness, assertiveness, ambition, accumulation of wealth), to societies where individuals pursue long term goals and dislike waste, to cultures that handle uncertainty easily, and to countries in which inequality in power is accepted by the less powerful in society. Also, we find more FDI outflows from countries in which people like to undertake independent initiatives but less FDI inflows into these countries. Many of these results conform to anecdotal beliefs on multinationals since these firms are highly competitive, undertake risky ventures such as $\mathrm{R} \& \mathrm{D}$ and international dealings, and are 
based around creative, intangible assets. Thus, these results provide an empirical motivation for expanding the research on the relationship between trade and culture into FDI and culture. ${ }^{5}$

In our analysis, we use three of the most commonly-used FDI datasets, all of which run from 1980 to 2000 . The first is the BEA data which covers bilateral US inbound and US outbound FDI stocks and affiliate sales. The second uses bilateral inbound FDI stocks where either the parent or host country belongs to the OECD. The third is provided by the World Bank (WB) and reports total inbound and total outbound FDI flows for a wide variety of countries. Our motivation for using these datasets is twofold. First, these are the most commonly employed datasets in the literature. Therefore this allows us to compare our results to the broadest set of existing literature. Second, by using XTFEVD, we are able to shed some light onto why the estimated impact of variables such as distance or common language vary from study to study. When using XTFEVD, we find that many of the conflicting results found from OLS regressions are resolved. This indicates not only the importance of the biases created by unobserved country heterogeneity, but that the extent and direction of these biases vary across datasets. Thus, using XTFEVD aids in filtering out such effects, yielding results that are more robust to alternative datasets than the OLS ones.

Beyond this, our analysis reveals several things. First, the introduction of fixed effects does have a significant impact on the magnitudes of the time-varying variables. In

\footnotetext{
${ }^{5}$ Related to our results on the level of FDI activity is the literature on cultural differences and the entry mode of multinationals. Tihanyi, Griffith and Russell (2005) provide an overview of this literature. Ionascu, Meyer and Estrin (2006) is a more recent addition that uses a composite measure of cultural differences composed from the same measures we use. Consistent with other studies, they find that multinationals tend towards greenfield investment (as opposed to acquisitions or joint ventures) when cultural differences are small.
} 
particular, parent and host population coefficients are biased towards zero. Looking at the time-invariant variables we find a number of sign reversals after employing the XTFEVD method. For example, in the US data, we find an inverted U shape for distance between the parent and host countries when not controlling for fixed effects. When doing so, we find a $U$ shape, a result also found in the OECD data. In addition, all three data sets, we find that excluding fixed effects introduces a downward bias in the estimated impact of parent and host country area.

The remainder of the paper is laid out as follows. Section 2 presents our empirical specification, describes our data and provides a brief discussion of the XTFEVD estimation procedure. Section 3 contains our empirical results. Section 4 concludes.

\section{Estimation Approach and Data}

This section details our regression specification, notable features of the data, and discusses our estimation techniques (in particular, the XTFEVD method).

\subsection{Regression Specification}

Our baseline estimation specification is the gravity model of FDI. This specification is the workhorse of the empirical FDI literature and has been used by numerous studies. ${ }^{6}$ This estimating equation uses information on the parent country $i$ and/or the host country $j$ to predict the amount of FDI activity in year $t$. This baseline specification is:

\footnotetext{
${ }^{6}$ Blonigen, Davies, Waddell, and Naughton (forthcoming), Gbetnkom (2006), Tong (2005), Gao (2005), Head and Ries (2005), di Giovanni (2005), Grubert and Mutti (2004), Brainard (1997), Eaton and Tamura (1994) are but a few examples. See Blonigen (2005) for a recent overview of the empirical FDI literature. It should be noted that there is also the specification proposed by Carr, Markusen, and Maskus (2001) which uses data in levels instead of logs and explicit interaction terms to control for the joint influence of some variables. However, Blonigen and Davies (2004) finds that due to the skewed nature of FDI data, this specification tends to yield non-normal residuals. The use of logs, however, reduces this problem while simultaneously allowing for implicit interactions between the various control variables.
} 
$\mathrm{FDI}_{i, j, t}=\alpha_{0}+\alpha_{1}$ ParentVariables $_{i, t}+\alpha_{2}$ HostVariables $_{j, t}+\alpha_{3}$ PairVariables $_{i, j, t}+\alpha_{4}$ Trend $_{t}+\varepsilon_{i, j, t}$

where non-dummy variables are measured in logs.

The parent variables include real GDP (Parent GDP), population (Parent Pop), a measure of trade costs (Parent TC), and area of the country (Parent Area). The host variables include a comparable set of controls (Host GDP, Host Pop, Host TC, and Host Area). In addition, we include a measure of host investment costs (Host Inv Cost). Beyond these parent- and host-specific variables, we also include a set of variables that use information from both the host and parent countries (the pair variables). Distance and its squared value (Distance $S q$ ) control for geographic proximity between countries. Two other variables (Island and Landlock) measure the number of island nations or landlocked nations in the country pair. As these are often significant in regressions of bilateral trade, to the extent that these are positively correlated with trade costs they can provide insight into the motivations behind FDI. ${ }^{7}$ Common Language is a dummy variable equal to one if there is a shared language between the countries. As with the trade and investment cost data, this is intended to capture some of the difficulty of doing business between the nations. Colony is a dummy variable equal to one when two countries share a common colonial history. This is intended to proxy for historical factors that increase the political and economic links between nations. To control for macroeconomic fluctuations, we control for the percentage change in the parent/host exchange rate from year $t-1$ to $t(X$ rate). ${ }^{8}$

In addition to these, we include a set of variables that compare information between the parent and host countries. Specifically, we compare the amount of schooling

\footnotetext{
${ }^{7}$ See Rose (2004) for an example of these in a trade regression. There, he finds that landlocked and island countries have less trade.

${ }^{8}$ Note that, since this is often negative, unlike the other variables this is not measured in logs.
} 
and cultural aspects as defined by Hofstede (1980) and Hofstede and Bond (1988) across countries by subtracting the host value of the variable in question from the parental value. Doing so, however, creates two difficulties. First, when the parental value is less than the host value, the difference is negative and we cannot take the log of a negative value. Second, and potentially more important, there is the issue raised by Blonigen, Davies, and Head (2003) regarding deviations from zero. In that paper, they point out that when estimating the effect of skill asymmetries on FDI, it is important to control for not just skill differences, but for differences from zero as the estimated impact of a movement away from zero can reduce FDI regardless of whether this is a movement into the positive range (where parent schooling is greater than host schooling, a positive difference) or into the negative range (where parent schooling is less than host schooling, a negative difference). One possible way to deal with this is to use absolute value of the difference. However, as Carr, Markusen, and Maskus (2003) note, this unnecessarily restricts the slope of this difference variable to be the same on either side of zero. Therefore, we instead use an approach similar to that of Markusen and Maskus (2002), where we include two separate variables, one for positive differences and one for negative differences. This allows us to see whether it is a deviation from zero that matters (in which case both should have the same sign) or not. In the gravity model, where variables are measured in logs, doing so also eliminates the problem of taking the log of a negative difference. Thus, our additional pair variables include differences in schooling (School), and differences on five cultural aspects: power distance $(P D)$, individualism (Independence), masculinity (Masculinity), uncertainty tolerance (Uncertainty), and longterm orientation (Time). These are discussed in more detail below. Each of these appears 
once for a positive difference (Diff Pos) and once for a negative difference (Diff Neg) for a total of twelve variables. Note that, with the exception of the school differences, these do not vary over time. Finally, we include a time trend (Trend).

In contrast to the bilateral US and OECD datasets, the WB data do not include information on the parent countries for the inbound data or the host countries for the outbound data. Therefore, in these regressions we are restricted to the host variables or the home variables respectively. We also cannot use the difference variables and therefore simply use the values of these variables for the country in question.

\subsection{Data}

In the Data Appendix, Table A1 contains a description of the units and sources for each of the variables. Table A2 contains summary statistics for each of the three data sets. Table A3 reports the list of parent and host countries used. ${ }^{9}$ While we refer the interested reader to the appendix for details, there are five aspects of the data that warrant discussion here.

We use three measures of FDI activity: real affiliate sales, real FDI stocks, and real FDI flows. ${ }^{10}$ The first is preferable for two reasons. First, it captures the value of FDI activity and therefore helps to control for differences in the technology across firms. Second, sales are the current value of the activity whereas stocks are the accumulated value of investment flows over time. As such, stock measures are dependent upon how historical values are measured. The upside of the stock and flow measures, however, is their availability. Our goal in this paper is to use commonly-employed variables -

\footnotetext{
${ }^{9}$ Note that in the World Bank data, the same countries appear in both the inbound and outbound samples, thus the difference in the number of observations is due to differences in missing years between the samples.

${ }^{10}$ Both were converted to constant 2000 US dollars using the chain-type price index for gross domestic investment obtained from the Economic Report to the President (US, 2007).
} 
including FDI measures - in order to enhance comparability between our results and those elsewhere. However, the only commonly-available sales data are for the US. Therefore for the OECD we are forced to use FDI stocks. ${ }^{11}$ For the World Bank data, we must use net inflows and net outflows of FDI. ${ }^{12}$ Another item to be aware of is that even in the US data, one can obtain different results for sales and stocks (see Davies, forthcoming, for an example). One contribution of this paper is that when we use the XTFEVD, we find comparable results for the US stock and sales results, even though OLS gives us different estimated signs for some variables across these datasets.

Second, it is important to note that the US data includes both inbound and outbound data. Therefore, in these data we include a dummy variable Inbound which is equal to one if the observation is for US inbound FDI. An alternative to combining the inbound and outbound data is to run separate regressions for each. In unreported results we did just this. On the whole, we found insignificance for the US-only variables but roughly similar signs on the pair variables as in the reported results. ${ }^{13}$ However, due to the drop in the number of observations, we the estimated coefficients were generally less significant than those found here. Similar to the US data, the OECD data reports FDI stocks inbound into an OECD country or outbound from and OECD country. When both countries are OECD countries, we have two observations on FDI. Due to differing definitions of FDI, the exchange rate used to convert the amount, and other reporting method differences, these two measures often differ. Therefore when two observations

\footnotetext{
${ }^{11}$ It is worth noting that even within the US data, FDI stock information is available for a wider selection of countries.

${ }^{12}$ A positive net inflow of FDI for country $i$ is an increase in the stock of FDI held by foreign investors in country $i$. A positive net outflow of FDI for country $i$ is an increase in the stock of FDI held by $i$ 's investors overseas. Thus, these are not the difference between inbound and outbound FDI.

${ }^{13}$ These alternative results are available on request.
} 
were available, we used the inbound data. ${ }^{14}$ As with the US results, to allow for differences in the average level of FDI between the inbound and outbound sources, we include a dummy variable Inbound.

Third, given the importance of trade costs in differentiating between motivations for FDI, it is important to consider the construction of our trade cost measure. In our data, a country's trade cost is the log of GDP divided by the sum of exports and imports (i.e. one over openness). This proxy is admittedly rough, in particular since large countries tend to trade less than small countries. However, we use this variable because it is both available for a large number of countries and is frequently used elsewhere. Likewise, distance, which is measured as the kilometers between capital cities, is at best an approximation of the distance between countries. Alternative measures use the distance between geographic centers or between economic centers. However, again, distance between capitals is the most widely measure of distance and we therefore use it here.

Fourth, our measure of investment costs comes from the Business Environment Risk Intelligence S.A. and is measured as the inverse of a composite index comprising operations risk index, political risk index and remittance and repatriation factor index. ${ }^{15}$ This variable limits the time series in our data to, depending on the country pair, 1980 to 2000. In unreported results, we excluded this variable in order to extend the time dimension of our data to as long as 1966-2005. This did not, however, qualitatively alter our results and, given the significance of the variable, we only report those results including it.

\footnotetext{
${ }^{14}$ When using only inbound data, the signs and significance of the coefficients from the XTFEVD regression match those for the OECD XTFEVD results with the exception that both parent and host trade costs are significantly positive.

${ }^{15}$ For more information see http://www.beri.com.
} 
Finally, given their relative unfamiliarity, our cultural variables deserve more detailed description. To capture the cultural characteristics of a country we use the five cultural dimensions identified by Hofstede to affect the behavior of individuals and organizations (Hofstede 1980, and Hofstede and Bond 1988). The first of these is power distance $(P D)$, which indicates the degree to which the less powerful segment of a society expects and accepts that power is distributed unequally. In countries that score high on this dimension individuals consent to a less equal society and organizations are likely to have centralized, top-down control. Second, we use the individualism measure (Independence). This variable reflects the extent to which people follow a group or organization. Countries with high values on individualism are those in which people act independently and pursue independent initiatives. Third, masculinity (Masculinity) ascertains the values around which a society is built: masculinity (e.g. competitiveness, assertiveness, ambition, accumulation of wealth) or femininity (e.g. relationships, quality of life). High scores are for societies with masculine traits. Fourth, uncertainty tolerance (Uncertainty) indicates the extent to which individuals value predictability. If a country scores high on uncertainty tolerance, the people in the country prefer rules and structured situations and are likely to avoid uncertain situations. Finally, long-term orientation (Time) measures to what extent people value thrift and perseverance. Cultures that attach a high importance to the past and present, such as those oriented on respect for tradition and fulfillment of social obligations score low on this dimension while cultures in which people are patient in waiting for results and value thrift receive high scores.

\subsection{Estimating Procedures}


For each dataset, we utilize three estimating procedures. First, as is common, we use OLS. Second, we include parent country-host country pair fixed effects (or simply country fixed effects in the WB data). As can be seen, many of our variables do not vary over time and we are unable to include them when using the standard fixed effects procedure. This is the purpose of utilizing the third method, the panel fixed effects with vector decomposition (XTFEVD) method. As this method is relatively new, it is useful to provide an overview of its workings in the context of our model.

The XTFEVD estimation procedure is a three-step estimator. The first step estimates a fixed effects regression with only the time-varying variables to obtain estimated country pair fixed effects (referred to as the unit effects). It is important to note that these estimated unit effects include both the impact of time-invariant unobservables as well as time-invariant observables (such as distance or area). The second step decomposes these estimated unit effects into an explainable part (attributed to the timeinvariant observables) and an unexplainable part (Residuals $s_{i, j, t}$ ) using OLS. The third stage then uses a pooled OLS that includes the time-varying variables, the time-invariant observables, and the time-invariant unexplainable Residuals $s_{i, j, t}$. This then yields the equivalent of a fixed effects estimator, with the exception that the time-invariant effects are decomposed into its observable and unobservable components. Of particular importance is that the procedure developed by Plümper and Troeger (forthcoming) is consistent and, as they demonstrate with Monte Carlo simulations, more efficient than other estimators attempting a similar decomposition. ${ }^{16}$ Given the relatively short time frame of FDI data, this efficiency is a valuable attribute of the technique.

\footnotetext{
${ }^{16}$ See Plümper and Troeger (forthcoming) for a detailed discussion on these other estimators as well as the Monte Carlo simulations.
} 


\section{Results}

In this section, we present our results. We begin with those for the bilateral US data, move to those from the bilateral OECD data, and then to those from the unilateral World Bank data. Finally, given the insights obtained from the World Bank results, we then return to the US and OECD data for a final set of results.

\subsection{US Results}

Table 1 presents our estimates from the US data. The first three columns report results when using FDI stocks, the last three report the results when using affiliate sales. Columns (1) and (4) contain the OLS results. Comparing these, we see that several estimates are consistent between the stock and sales results. In particular, FDI activity is largest between parent and host countries with large GDPs and small populations. In addition, higher trade costs seem to reduce FDI. This would be consistent with a vertical motivation behind FDI with the US. By way of contrast, however, Island is significantly positive in the stock results. Given that this is identified as a trade barrier by Rose (2004), this indicates the presence of horizontal FDI. Turning to the distance variables, the stock results indicate an inverted $U$ shape (where the coefficients imply a negative effect for distance for all countries in the sample) whereas the sales results find no significant impact from distance. Thus, while there are similarities between the samples there are also many notable differences. Other differences include a perplexing positive effect of host investment costs in the sales data but an insignificant impact in the stock results. In addition, having a schooling deficient parent is a detriment to FDI in the sales results but not in the stock results. As for the cultural variables, with the exception of the 
independence variables which are only significant in the stock data, the signs of the estimated coefficients are consistent between samples. Finally, the area variables indicate that more FDI activity comes from small parents and that host size has no impact on FDI.

Columns (2) and (3) employ fixed effects instead of OLS. Now, in contrast to the OLS results, the only difference between the stock and sales data is in the host trade cost which is significantly negative in the sales data but (just) insignificantly negatively in the stock data while the reverse is true for parent population. This would seem to suggest that including country-pair fixed effects is capable of eliminating many of the differences between samples. This seeming similarity, however, is somewhat misleading because many of the variables that differed in the OLS sample cannot be included in this fixed effects regression. Looking at the impact of the fixed effects on the magnitude of the coefficients, we see that in the stock data, including fixed effects lowers the coefficients on parent GDP, parent population, parent trade costs, and host population but increases the coefficient on host trade costs. The sales data, however, sees the coefficients on parent population, parent trade costs, and host trade costs moving in the opposite direction. However, similar to the stock data, the estimate on host population falls. We are unable to comment the extent to which the time-invariant variable estimates may be biased by the omission of unobserved factors since they cannot be included in the fixed effects estimation.

With this in mind, we now turn to the XTFEVD results from columns (3) and (6). In terms of the time-varying variables, as expected, we find similar signs and magnitudes between the fixed effects and XTFEVD results. Notably, however, the only difference between the two is that host investment costs are significantly negative in the stock 
results but insignificant in the sales results. Turning to the time-invariant variables, however, we find a number of significant changes between their OLS coefficients and these which correct for unobservable time-invariant factors. Looking at the geographic variables, we now find a $\mathrm{U}$ shape for distance which, given the estimates, indicates that more FDI takes place between distant countries. In the US data, these coefficients mean that there are no country pairs sufficiently close for distance to have a negative effect. This is suggestive of horizontal FDI and the opposite of what is found in the OLS results. The other geographic trade cost measures -including Island and Landlock - now suggest that trade barriers reduce FDI. This is more consistent with a vertical motivation for FDI. Since the aggregate data likely includes both horizontal and vertical style FDI, it is not surprising that we find evidence of both. Turning to the other trade cost measures, Common Language and Colony, also find significant changes. Specifically, whereas the OLS results indicate that a common language increases FDI but colonial ties have no effect, the XTFEVD results reveal the reverse. Thus, the time-invariant trade cost variables appear to be significantly impacted by the omission of fixed effects.

Turning to the culture variables, we find two large changes. OLS indicated that FDI was greatest when the Independence and Uncertainty values for the parent were low relative to the host, the XTFEVD results indicate the reverse. In addition, with the exception of Uncertainty Diff Neg, which is negative in the stock results but insignificant in the sales results, the difference variables all have the same sign across the two samples. Thus, the XTFEVD results indicate that FDI activity is greatest when the parent's $P D$, Masculinity, or Time levels are low relative to the host's and when the parent's Independence and Uncertainty levels are high relative to the host's. Interestingly, it is 
worth noting that these patterns reject the concern that cultural differences, i.e. symmetric deviations from zero, drive FDI.

Finally, with the exception of the Parent Area in the sales results, we find that more FDI takes place when the parent and/or the host are large. This suggests that natural resource abundance may be important for investment decisions and matches the findings of Coughlin, Terza, and Arromdee (1991). In addition, the significant effect on Residuals indicates that the unexplainable component of the fixed effects is indeed important for explaining FDI patterns. Finally, in the XTFEVD results, the additional controls (Inbound, X-Rate, Year) are all insignificant.

\subsection{OECD Results}

Table 2 presents a comparable set of regressions using the OECD data rather than the US data. First, comparing the OLS results from the OECD regression to their counterpart in the US data (column (1) of Table 1), we see several noticeable differences, especially with regards to the time-invariant variables. In particular, rather than the inverted $\mathrm{U}$ for distance in the US results, the OECD estimates indicate a U shape. In addition, the OECD data find a significant impact from Host Area and Colony. Furthermore, the OECD results find significantly negative effects from both Island and Landlock. Similar differences are found for the Uncertainty and Time variables, which suggest an opposite effect from the US results. Finally, Host Pop is insignificant in the OECD results instead of significantly negative.

Turning to the FE results, as in the US data, we find significant declines in the coefficients for Parent Pop and Host Pop suggesting that these are biased upwards by the omitted, time-invariant unobservables. Unlike the US data, we find that the omission of 
fixed effects biased our Parent TC and Host TC variables downwards. We also find that including fixed effects eliminates the significance of the schooling variables.

Finally, column (3) presents the XTFEVD results from the OECD data. As in the US data, when comparing these OECD XTFEVD with the OLS results in column (1), we find several changes. Most notably, we now find both Area variables are significantly positive. In addition, we see a reversal in the predicted patterns of the Independence and Time difference variables and the Common Language dummy. This again indicates that the omitted fixed effects led to biases here. It is worth noting that the direction of these biases are shared between the US and OECD results. Thus, using XTFEVD is helpful in resolving inconsistencies across both of the US datasets and the OECD dataset. In fact, after accounting for the fixed effects through XTFEVD, with the exception of the Parent $T C$ and PD Diff Neg, there are no differences in the signs of the significant estimates found in the three samples. It is worth recognizing, however, that the OECD results are relatively more consistent between the OLS and XTFEVD results than the US data are. This suggests that estimates obtained from data with more variety in country pairs may be less susceptible to these omitted variable biases than those from data where a single country is common to all observations.

\subsection{World Bank Results}

Table 3 presents the estimates from the World Bank data. Columns (1) through (3) are the estimates using inbound FDI data. Thus, in these columns variables correspond to the host values. Columns (4) through (6) are for the outbound FDI data. In these three columns, the variables are for the parent country. As before, columns (1) and 
(4) present OLS estimates, columns (2) and (5) report fixed effects estimates, and columns (3) and (6) present the XTFEVD estimates.

Looking first at the time-varying variables, we find many similarities between the previous results and these. As before, most FDI activity goes to or comes from large economies with small populations and that this latter effect is enhanced by the inclusion of fixed effects. This pattern, including the bias, is consistent with the bilateral FDI results above. Consistent with the US results, more FDI goes to countries with low trade costs. Similar to the OECD findings, the effect of the parent's trade cost is biased downwards by the omission of fixed effects. Also similar to the previous results, we find that more FDI comes from countries with high schooling levels (at least when fixed effects are included). Somewhat surprisingly, we find that more FDI goes to countries with low skill levels, but this result is not robust to the inclusion of fixed effects. Thus, yet again, we find that the omission of unobserved time-invariant variables biases several standard time-varying control variables.

We also find that the omission of fixed effects biases many of the time-invariant variables. When using OLS, we find insignificant effects on Landlock in both the inbound and outbound data. Island, meanwhile, is insignificant in the inbound data but significantly positive in the outbound data. When using XTFEVD, however, we find the same results from the other data sets, namely that landlocked and island nations receive less investment. This is indicative of vertical FDI. There does not appear to be a significant bias in Area, however, which is positive throughout. This then also matches the bilateral data XTFEVD results. 
Looking at the cultural variables, the OLS results indicate several differences between the inbound and outbound sample. As with the US stock and sales data, this appears to be due to omitted fixed effects. When they are included in columns (3) and (6), we find the same predicted signs in each. These signs seem to indicate that more FDI comes from and goes to countries with high PD, Masculinity, and Time values and those with low Independence and Uncertainty values. Finally as in the US data, when using XTFEVD, neither $X$-rate nor Trend are significant.

\subsection{To Difference or Not to Difference?}

We see an important difference between the bilateral data results and those from the World Bank data when comparing the difference variables to their counterparts in Table 3. For example, the bilateral data indicate that FDI activity is greatest when the parent has a high $P D$ measure compared to that of the host (i.e. when the difference between the two is large and positive). Looking at the World Bank results, this might lead one to expect that a given country's $P D$ would have a positive effect on its outbound FDI but a negative effect on its inbound FDI. ${ }^{17}$ As Table 3 shows, this is not the case. Therefore, for our final set of results, we return to the bilateral US and OECD data but replace the difference terms with a set of parent and host variables. Table 4 shows the results when also controlling for fixed effects through XTFEVD.

As in the World Bank results, we find that many of the formerly differenced variables exhibit the same sign for the parent and host countries. In particular, FDI is greatest when both countries have high PD scores, high Masculinity scores, and low Uncertainty scores. These results match the World Bank results and imply that using

\footnotetext{
${ }^{17}$ This is only approximately correct because it is primarily true for countries with either very high or very low values when compared to the sample average.
} 
difference terms is inappropriate for these variables. For the stock regressions (columns (1) and (3)) we find that the parent and host Independence coefficients have the opposite signs, implying that FDI is greatest when the parent has a high Independence score and the host has a low one. A similar result is found for schooling in the US data. This is consistent with the earlier results, suggesting that using differences may be appropriate for these two variables. In all three regressions Parent Time is positive and significant (consistent with the World Bank data). Host Time, however, varies across the three. This suggests that, at least for the US results, a difference term may be appropriate as this is consistent with the results found there. Finally, the remaining variables, both timevarying and time-invariant, are relatively unchanged relative to the previous results.

\section{Conclusions}

The goal of this paper has been to employ the panel fixed effects with vector decomposition method developed by Plümper and Troeger (forthcoming) to examine the extent to which the omission of fixed effects gives misleading coefficients in FDI regressions. We find that the resulting biases can be quite significant and that they vary across the three most commonly used FDI datasets. As a result, when including fixed effects, we find much more consistency in the estimates of time-invariant variables across data sets. In general, these new estimates find additional evidence of the importance of trade costs. In particular, geographic variables such as whether the parent or host country is landlocked or an island nation, which Rose (2004) finds are significant deterrents to trade, also seem to deter FDI. This is suggestive of vertical FDI. Nevertheless, other variables, especially the distance between capitals, indicates horizontal FDI. That we find 
mixed results is not surprising, as industry-level results from papers such as Blonigen, Davies, Waddell, and Naughton (forthcoming) find that even within US data there are significant differences in the motivation behind FDI across industries. Thus, when (as in many papers) we aggregate across industries, one might expect evidence of both. What is notable, however, is that since XTFEVD yields far more comparable results across our datasets, that using country pair fixed effects may be very useful in removing the problems this variation causes when industry level data are not available.

In addition to our main results, we find that the cultural variables constructed by Hofstede (Hofstede, 1980; Hofstede and Bond, 1988; Hofstede, 2001) are significant determinants of FDI. This suggests that further research into the interaction between culture and international economic activity is a meaningful one and that further understanding of the ways in which these relate can have useful policy implications. 


\section{References}

Arromdee Vachira, Coughlin Cletus C., Terza Joseph V. (1991). The Review of Economics and Statistics, Vol. 73, No. 4, 675-683.

Baltagi, Badi H., Peter Egger, and Michael Pfaffermayr. (Forthcoming) "Estimating Models of Complex FDI: Are There Third-Country Effects?" Journal of Econometrics.

Bureau of Economic Analysis; www.bea.doc.gov/bea/di/dilfdibal.htm.

BERI Business Environment Risk Intelligence; www.beri.com.

Bergstrand, Jeffrey H. and Peter Egger. (forthcoming) "A Knowledge-and-PhysicalCapital Model of International Trade Flows, Foreign Direct Investment, and Multinational Enterprises." Journal of International Economics.

Blonigen, B. A. (2005). "A Review of the Empirical Literature on FDI Determinants," Atlantic Economics Journal, 33, 383-403.

Blonigen, Bruce A., Ronald B. Davies, and Keith Head. (2003) "Estimating the Knowledge-Capital Model of the Multinational Enterprise: Comment," American Economic Review 93(3): 980-94.

Blonigen, Bruce A. and Ronald B. Davies. (2004) "The Effects of Bilateral Tax Treaties on US FDI Activity," International Tax and Public Finance 11 (5), 601-22.

Blonigen, Bruce A., Ronald B. Davies, Glen R. Waddell and Helen Naughton. "FDI in Space: Spatial Autoregressive Relationships in Foreign Direct Investment," forthcoming European Economic Review.

Brainard, S. Lael. (1997) "An Empirical Assessment of the Proximity-Concentration Trade-off Between Multinational Sales and Trade," American Economic Review 87(4): 520-44.

Carr, David L., James R. Markusen, and Keith E. Maskus. (2001) "Estimating the Knowledge-Capital Model of the Multinational Enterprise." American Economic Review 91(3), 693-708.

Carr, David L., James R. Markusen and Keith E. Maskus (2003) "Estimating the Knowledge-Capital Model of the Multinational Enterprise: Reply," American Economic Review 93: 995-1001.

Davies, Ronald B. "Hunting High and Low for Vertical FDI," forthcoming Review of International Economics. 
di Giovanni J (2005). What drives capital flows? The case of cross-border M\&A activity and financial deepening. Journal of International Economics 65 (1): 127-149.

Eaton, Jonathan and Akiko Tamura. (1994) "Bilateralism and Regionalism in Japanese and US Trade and Direct Foreign Investment Patterns," Journal of the Japanese and International Economies 8(4), 478-510.

Ekholm, Karolina, Rikard Forslid, and James R. Markusen. (forthcoming) "ExportPlatform Foreign Direct Investment," Journal of European Economics Association.

Gao Ting (2005). Foreign direct investment in China: How big are the roles of culture and geography? Pacific Economic Review 10 (2): 153-166 JUN 2005.

Grubert, Harry and Mutti, John (2004). Empirical asymmetries in foreign direct investment and taxation. Journal of International Economics. Volume 62, Issue 2, March 2004, Pages 337-358.

Gbetnkom D. (2006). On the empirics of market integration in ECOWAS. Journal of Policy Reform. 9 (4): 289-303..

Head K, and Ries J (2005). Judging Japan's FDI: The verdict from a dartboard model. Journal of The Japanese and International Economies 19 (2): 215-232.

Helpman, Elhanan. (1984) "A Simple Theory of International Trade with Multinational Corporations," Journal of Political Economy 92(3), 451-71.

Hofstede, Geert (1980) Culture’s Consequences. New York: Sage.

Hofstede, Geert and M.H. Bond (1988) "The Confucius Connection: From Cultural Roots to Economic Growth," Organizational Dynamics 16: 4-21.

Hofstede, Geert (2001) Culture's Consequences: Comparing Values, Behaviors, Institutions, and Organizations across Nations. New York: Sage.

Ionaşcu, D., K.E. Meyer and S. Estrin (2006) "Varieties of Institutional Distance and International Business Strategies in Emerging Economies," revise and resubmit, Journal of International Business Studies.

Janeba, Eckhard. European Economic Review International Trade and Consumption Network Externalities (forthcoming).

Markusen, James R. (1984) "Multinationals, Multi-Plant Economies, and the Gains from Trade," Journal of International Economics 16(3-4), 205-26.

Markusen, James R. (2002) Multinational Firms and the Theory of International Trade. Cambridge and London: MIT Press. 
Markusen, James R. and Keith E. Maskus. (2002) "Discriminating among alternative theories of the multinational enterprise." Review of International Economics 10 (4), 694-707.

Plümper, Thomas, and Troeger, Vera E. (2007). Efficient Estimation of Time-Invariant and Rarely Changing Variables in Finite Sample Panel Analyses with Unit Fixed Effects. Political Analysis..

Rose Andrew K. (2004). Do We Really Know That the WTO Increases Trade? American Economic Review. 94 (1), 98-114.

Summers, Robert and Alan Heston. (1991). "The Penn-World Table (Mark 5): An Expanded Set of International Comparisons, 1950 - 1988." Quarterly Journal of Economics, 106, 327-368.

Tihanyi, L., Griffith, D.A. and Russel, C.J. (2005): The Effect of Cultural Distance on Entry Mode Choice, International Diversification, and MNE Performance: A MetaAnalysis," Journal of International Business Studies 36: 270-283.

Tong Sarah. Y (2005) Ethnic Networks in FDI and the Impact of Institutional Development, Review of Development Economics 9 (4), 563-580.

US Government Printing Office (2007) Economic Report to the President, Washington D.C.

WDI World Development Indicators; http://publications.worldbank.org/WDI/

Yeaple, Stephen R. (2003) "The Complex Integration Strategies of Multinationals and Cross Country Dependencies in the Structure of Foreign Direct Investment," Journal of International Economics 60(2), 293-314. 
Table 1: US Results

\begin{tabular}{|c|c|c|c|c|c|c|}
\hline & \multicolumn{3}{|l|}{ Stock } & \multicolumn{3}{|l|}{ Sales } \\
\hline & (1) & (2) & (3) & (4) & $(5)$ & (6) \\
\hline & OLS & FE & XTFEVD & OLS & $\mathrm{FE}$ & XTFEVD \\
\hline \multirow[t]{2}{*}{ Parent GDP } & $2.186 * * *$ & $1.732 * * *$ & $1.608 * * *$ & $2.748 * * *$ & $3.099 * * *$ & $3.139 * * *$ \\
\hline & $(24.75)$ & $(6.48)$ & $(9.60)$ & $(29.49)$ & $(4.82)$ & $(13.39)$ \\
\hline \multirow[t]{2}{*}{ Parent Pop } & $-0.699 * * *$ & $-7.148^{* * *}$ & $-7.090 * * *$ & $-1.027 * * *$ & -2.084 & $-2.002 * * *$ \\
\hline & $(7.10)$ & $(8.20)$ & $(15.42)$ & $(9.41)$ & $(1.55)$ & $(3.01)$ \\
\hline \multirow[t]{2}{*}{ Parent TC } & $-6.588 * * *$ & $-9.624 * * *$ & $-12.225 * * *$ & $-15.798 * * *$ & $-8.206 * *$ & $-8.253 * * *$ \\
\hline & $(4.13)$ & $(4.15)$ & $(8.45)$ & $(5.39)$ & $(2.04)$ & $(3.92)$ \\
\hline \multirow[t]{2}{*}{ Host GDP } & $1.446 * * *$ & $1.737 * * *$ & $1.675 * * *$ & $1.972 * * *$ & $2.118 * * *$ & $2.125 * * *$ \\
\hline & $(17.69)$ & $(9.46)$ & $(10.00)$ & $(19.50)$ & $(5.45)$ & $(9.20)$ \\
\hline \multirow[t]{2}{*}{ Host Pop } & $-0.800 * * *$ & $-2.288 * * *$ & $-2.238 * * *$ & $-1.179 * * *$ & $-3.682 * * *$ & $-3.699 * * *$ \\
\hline & $(7.54)$ & $(5.30)$ & $(4.78)$ & $(10.17)$ & $(4.64)$ & $(5.44)$ \\
\hline \multirow[t]{2}{*}{ Host TC } & $-3.807 * *$ & -2.030 & $-2.625 *$ & $-5.042 * *$ & $-10.014 * * *$ & $-9.950 * * *$ \\
\hline & $(2.26)$ & $(1.46)$ & $(1.84)$ & $(2.36)$ & $(3.72)$ & $(4.80)$ \\
\hline \multirow{2}{*}{ Host Inv Cost } & -0.101 & -0.547 & $-0.545^{*}$ & $0.675^{*}$ & 0.101 & 0.094 \\
\hline & $(0.24)$ & $(1.56)$ & $(1.70)$ & $(1.68)$ & $(0.21)$ & $(0.19)$ \\
\hline \multirow[t]{2}{*}{ School Diff Neg } & 0.132 & $-0.285 * * *$ & $-0.283 * * *$ & $-0.417 * * *$ & $-0.327 * *$ & $-0.339 * * *$ \\
\hline & $(1.24)$ & $(3.51)$ & $(3.39)$ & $(2.78)$ & $(2.03)$ & $(2.88)$ \\
\hline \multirow[t]{2}{*}{ School Diff Pos } & $0.851 * * *$ & $0.448 * * *$ & $0.444 * * *$ & $0.869 * * *$ & $0.421 * * *$ & $0.419 * * *$ \\
\hline & $(6.16)$ & $(5.17)$ & $(5.05)$ & $(6.78)$ & $(5.16)$ & $(3.49)$ \\
\hline \multirow[t]{2}{*}{ PD Diff Neg } & $0.283 * * *$ & & $2.149 * * *$ & $0.220 * * *$ & & $0.063 * * *$ \\
\hline & $(5.05)$ & & $(2.77 \mathrm{e}+12)$ & $(3.17)$ & & $(6.16 \mathrm{e}+10)$ \\
\hline \multirow[t]{2}{*}{ PD Diff Pos } & $-0.470 * * *$ & & $-0.302 * * *$ & $-0.380 * * *$ & & $-0.982 * * *$ \\
\hline & $(8.30)$ & & $(3.89 \mathrm{e}+11)$ & $(4.67)$ & & $(9.65 \mathrm{e}+11)$ \\
\hline \multirow[t]{2}{*}{ Independ. Diff Neg } & $0.165 * *$ & & $-1.927 * * *$ & -0.130 & & $-1.701 * * *$ \\
\hline & $(2.22)$ & & $(251.85)$ & $(1.57)$ & & $(140.23)$ \\
\hline \multirow[t]{2}{*}{ Independ. Diff Pos } & $-0.154 * *$ & & $3.195 * * *$ & 0.056 & & $0.868 * * *$ \\
\hline & $(2.53)$ & & $(109.84)$ & $(0.79)$ & & $(22.24)$ \\
\hline \multirow[t]{2}{*}{ Masculinity Diff Neg } & $0.274 * * *$ & & $2.723 * * *$ & $0.316^{* * *}$ & & $0.927 * * *$ \\
\hline & $(4.86)$ & & $(93.44)$ & $(4.78)$ & & $(23.53)$ \\
\hline \multirow[t]{2}{*}{ Masculinity Diff Pos } & $-0.364 * * *$ & & $-2.023 * * *$ & $-0.334 * * *$ & & $-1.234 * * *$ \\
\hline & $(6.45)$ & & $(66.36)$ & $(5.28)$ & & $(29.50)$ \\
\hline \multirow[t]{2}{*}{ Uncertainty Diff Neg } & $0.483 * * *$ & & $-1.364 * * *$ & $0.362 * * *$ & & 0.007 \\
\hline & $(7.27)$ & & $(44.20)$ & $(4.66)$ & & $(0.16)$ \\
\hline \multirow[t]{2}{*}{ Uncertainty Diff Pos } & $-0.501 * * *$ & & $0.810 * * *$ & $-0.453 * * *$ & & $0.108 * * *$ \\
\hline & $(7.44)$ & & $(37.92)$ & $(5.55)$ & & $(3.78)$ \\
\hline \multirow[t]{2}{*}{ Time Diff Neg } & $-0.378 * * *$ & & $-1.665 * * *$ & $-0.338 * * *$ & & $-0.862 * * *$ \\
\hline & $(11.25)$ & & $(78.60)$ & $(6.86)$ & & $(30.55)$ \\
\hline \multirow[t]{2}{*}{ Time Diff Pos } & $0.336^{* * *}$ & & $2.021 * * *$ & $0.481 * * *$ & & $0.892 * * *$ \\
\hline & $(9.29)$ & & $(77.62)$ & $(8.61)$ & & $(25.41)$ \\
\hline \multirow[t]{2}{*}{ Parent Area } & $-0.340 * * *$ & & $2.917 * * *$ & $-0.156 * *$ & & -0.019 \\
\hline & $(7.81)$ & & $(111.45)$ & $(2.47)$ & & $(0.55)$ \\
\hline Host Area & -0.008 & & $0.576^{* * *}$ & -0.042 & & $1.181 * * *$ \\
\hline & $(0.19)$ & & $(31.79)$ & $(0.98)$ & & $(49.74)$ \\
\hline Distance & $5.186^{* * *}$ & & $-6.226 * * *$ & -0.676 & & $-11.671 * * *$ \\
\hline & $(3.29)$ & & $(353.70)$ & $(0.43)$ & & $(508.02)$ \\
\hline
\end{tabular}




\begin{tabular}{|l|l|l|l|l|l|l|}
\hline Distance Sq. & $-0.368^{* * *}$ & & $0.481^{* * *}$ & 0.060 & & $0.851^{* * *}$ \\
\hline & $(3.49)$ & & $(28.04)$ & $(0.58)$ & & $(37.40)$ \\
\hline Colony & -0.261 & & $10.704^{* * *}$ & -0.346 & & $3.826^{* * *}$ \\
\hline & $(1.44)$ & & $(589.17)$ & $(1.54)$ & & $(161.91)$ \\
\hline Common Lang & $0.400^{* * *}$ & & -0.939 & $0.755^{* * *}$ & & 0.519 \\
\hline & $(2.67)$ & & $(1.25)$ & $(3.68)$ & & $(0.53)$ \\
\hline Island & $0.476^{* * *}$ & & $-0.918^{* * *}$ & -0.221 & & $-1.665^{* * *}$ \\
\hline & $(2.67)$ & & $(18.65)$ & $(1.18)$ & & $(25.78)$ \\
\hline Landlock & -0.132 & & $-2.103^{* * *}$ & -0.041 & & $-0.769^{* * *}$ \\
\hline & $(1.14)$ & & $(21.54)$ & $(0.37)$ & & $(5.94)$ \\
\hline Inbound & $1.161^{* * *}$ & & 0.000 & $1.780^{* * *}$ & & -0.000 \\
\hline & $(5.78)$ & & $(0.00)$ & $(6.15)$ & & $(0.00)$ \\
\hline X-rate & $0.000^{* * *}$ & -0.000 & -0.000 & $0.000^{* * *}$ & -0.000 & -0.000 \\
\hline & $(3.44)$ & $(1.37)$ & $(0.00)$ & $(4.30)$ & $(1.10)$ & $(0.00)$ \\
\hline Year & $-0.015^{* *}$ & $0.057^{* * *}$ & 0.056 & $-0.078^{* * *}$ & $-0.063 * *$ & -0.065 \\
\hline & $(2.29)$ & $(4.78)$ & $(1.10)$ & $(6.57)$ & $(2.58)$ & $(0.97)$ \\
\hline Residuals & & & $1.000^{* * *}$ & & & $1.000^{* * *}$ \\
\hline & & & $(278.82)$ & & & $(88.71)$ \\
\hline Constant & $-55.341^{* * *}$ & $-94.569^{* * *}$ & $-125.19^{* * *}$ & $71.655^{* * *}$ & $59.059^{*}$ & $81.068^{* * *}$ \\
\hline & $(4.30)$ & $(7.08)$ & $(40.08)$ & $(3.25)$ & $(1.77)$ & $(20.02)$ \\
\hline Observations & 1038 & 1038 & 1038 & 816 & 816 & 816 \\
\hline R-squared & 0.88 & 0.97 & 0.97 & 0.87 & 0.96 & 0.96 \\
\hline
\end{tabular}

Robust $t$-statistics reported in parentheses. $* * *$ significant at $1 \%$ level. $* *$ significant at $5 \%$ level. * significant at $10 \%$ level. 
Table 2: OECD Results

\begin{tabular}{|c|c|c|c|}
\hline & (1) & (2) & (3) \\
\hline & OLS & FE & XTFEVD \\
\hline \multirow[t]{2}{*}{ Parent GDP } & $2.432 * * *$ & $2.207 * * *$ & $2.242 * * *$ \\
\hline & $(57.68)$ & $(9.43)$ & $(12.85)$ \\
\hline \multirow[t]{2}{*}{ Parent Pop } & $-1.083^{* * *}$ & $-3.441 * * *$ & $-3.567 * * *$ \\
\hline & $(24.70)$ & $(4.46)$ & $(5.37)$ \\
\hline \multirow[t]{2}{*}{ Parent TC } & $-6.862^{* * *}$ & $8.664 * * *$ & $8.909 * * *$ \\
\hline & $(5.34)$ & $(5.19)$ & $(5.49)$ \\
\hline \multirow[t]{2}{*}{ Host GDP } & $0.709^{* * *}$ & $1.628 * * *$ & $1.674 * * *$ \\
\hline & (14.99) & $(7.20)$ & $(8.75)$ \\
\hline \multirow[t]{2}{*}{ Host Pop } & 0.010 & $-3.387 * * *$ & $-3.575 * * *$ \\
\hline & $(0.22)$ & $(4.54)$ & $(5.44)$ \\
\hline \multirow[t]{2}{*}{ Host TC } & $-14.489 * * *$ & 2.429 & 2.182 \\
\hline & $(11.48)$ & $(1.36)$ & $(1.36)$ \\
\hline \multirow[t]{2}{*}{ Host Inv Cost } & $-1.688 * * *$ & $-1.127 * * *$ & $-1.109 * * *$ \\
\hline & $(7.63)$ & $(3.50)$ & $(3.71)$ \\
\hline \multirow[t]{2}{*}{ School Diff Neg } & $-0.122 * * *$ & 0.012 & 0.008 \\
\hline & $(3.22)$ & $(0.31)$ & $(0.24)$ \\
\hline \multirow[t]{2}{*}{ School Diff Pos } & -0.013 & -0.023 & -0.027 \\
\hline & $(0.39)$ & $(0.74)$ & $(0.82)$ \\
\hline \multirow[t]{2}{*}{ PD Diff Neg } & $0.134^{* * *}$ & & $-0.499 * * *$ \\
\hline & $(4.06)$ & & \begin{tabular}{|c}
$(3377.09)$ \\
\end{tabular} \\
\hline \multirow[t]{2}{*}{ PD Diff Pos } & $-0.322 * * *$ & & $-0.024 * * *$ \\
\hline & $(10.39)$ & & $(3.18)$ \\
\hline \multirow[t]{2}{*}{ Independence Diff Neg } & $0.073^{* *}$ & & $-0.436 * * *$ \\
\hline & $(2.55)$ & & $(32.83)$ \\
\hline \multirow[t]{2}{*}{ Independence Diff Pos } & $-0.148 * * *$ & & $0.593 * * *$ \\
\hline & $(5.25)$ & & $(45.31)$ \\
\hline \multirow[t]{2}{*}{ Masculinity Diff Neg } & 0.028 & & 0.880 *** \\
\hline & $(1.11)$ & & $(68.47)$ \\
\hline \multirow[t]{2}{*}{ Masculinity Diff Pos } & $-0.201 * * *$ & & $-1.066 * * *$ \\
\hline & $(7.81)$ & & $(82.59)$ \\
\hline \multirow[t]{2}{*}{ Uncertainty Diff Neg } & $-0.098 * * *$ & & $-0.266 * * *$ \\
\hline & $(3.14)$ & & $(22.25)$ \\
\hline \multirow[t]{2}{*}{ Uncertainty Diff Pos } & -0.007 & & $0.495 * * *$ \\
\hline & $(0.22)$ & & $(41.41)$ \\
\hline \multirow[t]{2}{*}{ Time Diff Neg } & $0.189 * * *$ & & $-1.177 * * *$ \\
\hline & $(7.35)$ & & $(83.28)$ \\
\hline \multirow[t]{2}{*}{ Time Diff Pos } & 0.000 & & $1.344 * * *$ \\
\hline & $(0.02)$ & & $(95.62)$ \\
\hline \multirow[t]{2}{*}{ Parent Area } & $-0.039^{*}$ & & $1.114^{* * * *}$ \\
\hline & $(1.81)$ & & $(99.48)$ \\
\hline Host Area & $0.331 * * *$ & & $1.437 * * *$ \\
\hline
\end{tabular}




\begin{tabular}{|l|l|l|l|}
\hline & $(15.31)$ & & $(130.93)$ \\
\hline Distance & $-2.573^{* * *}$ & & $-5.229^{* * *}$ \\
\hline & $(6.32)$ & & $(622.82)$ \\
\hline Distance Sq. & $0.115^{* * *}$ & & $0.258^{* * *}$ \\
\hline & $(4.09)$ & & $(30.89)$ \\
\hline Colony & $0.640^{* * *}$ & & $3.870^{* * *}$ \\
\hline & $(5.84)$ & & $(21.92)$ \\
\hline Common Lang & $1.273^{* * *}$ & & $-0.750^{* * *}$ \\
\hline & $(16.15)$ & & $(62.44)$ \\
\hline Island & $-0.250^{* *}$ & & $-1.307^{* * *}$ \\
\hline & $(2.55)$ & & $(21.21)$ \\
\hline Landlock & $-0.334^{* * *}$ & & $-1.420^{* * *}$ \\
\hline & $(5.45)$ & & $(33.09)$ \\
\hline X-Rate & $-0.000^{* * *}$ & $0.000^{* * *}$ & 0.000 \\
\hline & $(3.27)$ & $(2.76)$ & $(0.01)$ \\
\hline Year & 0.005 & $0.073^{* * *}$ & $0.073^{* * *}$ \\
\hline & $(0.88)$ & $(7.19)$ & $(2.94)$ \\
\hline Inward & $0.286^{* * *}$ & 0.023 & $-0.068^{* *}$ \\
\hline & $(4.37)$ & $(0.36)$ & $(2.46)$ \\
\hline Residuals & & & $1.000^{* * *}$ \\
\hline & & & $(356.63)$ \\
\hline Constant & $-68.404^{* * *}$ & $-179.527^{* * *}$ & $-189.733^{* * *}$ \\
\hline & $(6.24)$ & $(14.57)$ & $(299.97)$ \\
\hline Observations & 5450 & 5450 & 5450 \\
\hline R-squared & 0.71 & 0.94 & 0.94 \\
\hline
\end{tabular}

Robust t-statistics reported in parentheses. $* * *$ significant at $1 \%$ level. ** significant at $5 \%$ level. * significant at $10 \%$ level. 
Table 3: World Bank Results

\begin{tabular}{|c|c|c|c|c|c|c|}
\hline & \multicolumn{3}{|l|}{ Inbound } & \multicolumn{3}{|l|}{ Outbound } \\
\hline & OLS & $\mathrm{FE}$ & XTFEVD & OLS & $\mathrm{FE}$ & XTFEVD \\
\hline \multirow[t]{2}{*}{ GDP } & $0.977 * * *$ & $1.371 * * *$ & $1.357 * * *$ & $2.254 * * *$ & $2.448 * * *$ & $2.467 * * *$ \\
\hline & $(11.30)$ & $(4.17)$ & $(4.19)$ & $(17.52)$ & $(5.82)$ & $(7.25)$ \\
\hline \multirow[t]{2}{*}{ Pop } & $-0.193 *$ & $-3.698 * * *$ & $-3.703 * * *$ & $-0.933 * * *$ & $-5.419 * * *$ & $-5.412 * * *$ \\
\hline & $(1.92)$ & $(4.46)$ & $(4.99)$ & $(6.75)$ & $(6.07)$ & $(5.73)$ \\
\hline \multirow[t]{2}{*}{$\mathrm{TC}$} & $-22.765 * * *$ & $-11.015 * * *$ & $-11.621 * * *$ & $-20.49 * * *$ & -2.508 & -1.909 \\
\hline & $(10.03)$ & $(3.47)$ & $(3.84)$ & $(8.25)$ & $(0.68)$ & $(0.59)$ \\
\hline \multirow[t]{2}{*}{ School } & $-0.768 * * *$ & -0.478 & -0.495 & -0.215 & $1.614 * * *$ & $1.613 * *$ \\
\hline & $(3.73)$ & $(0.79)$ & $(0.76)$ & $(0.88)$ & $(2.62)$ & $(2.49)$ \\
\hline \multirow[t]{2}{*}{ PD } & $0.240^{*}$ & & $3.723 * * *$ & $0.405 * * *$ & & $4.449 * * *$ \\
\hline & $(1.91)$ & & $(129.97)$ & $(3.00)$ & & $(174.57)$ \\
\hline \multirow[t]{2}{*}{ Independence } & $0.819 * * *$ & & $-0.733 * * *$ & 0.251 & & $-1.870 * * *$ \\
\hline & $(4.66)$ & & $(77.65)$ & $(1.23)$ & & $(199.42)$ \\
\hline \multirow[t]{2}{*}{ Masculinity } & 0.042 & & $3.334 * * *$ & $-0.174 *$ & & $4.304 * * *$ \\
\hline & $(0.37)$ & & $(33.77)$ & $(1.78)$ & & $(46.23)$ \\
\hline \multirow[t]{2}{*}{ Uncertainty } & -0.109 & & $-3.875 * * *$ & $-0.759 * * *$ & & $-5.012 * * *$ \\
\hline & $(0.57)$ & & $(41.70)$ & $(3.68)$ & & $(54.65)$ \\
\hline \multirow[t]{2}{*}{ Time } & -0.058 & & $1.155 * * *$ & $0.341 * *$ & & $2.189 * * *$ \\
\hline & $(0.40)$ & & $(15.93)$ & $(2.31)$ & & $(35.18)$ \\
\hline \multirow[t]{2}{*}{ Area } & $0.431 * * *$ & & $1.161 * * *$ & $0.143 * * *$ & & $0.952 * * *$ \\
\hline & $(9.87)$ & & $(10.01)$ & $(3.48)$ & & $(8.83)$ \\
\hline \multirow[t]{2}{*}{ Island } & 0.002 & & $-3.777 * * *$ & $0.408 * * *$ & & $-4.234 * * *$ \\
\hline & $(0.01)$ & & $(39.13)$ & $(2.94)$ & & $(44.73)$ \\
\hline \multirow[t]{2}{*}{ Landlock } & -0.046 & & $-3.092 * * *$ & 0.059 & & $-4.633 * * *$ \\
\hline & $(0.19)$ & & $(132.06)$ & $(0.27)$ & & $(220.83)$ \\
\hline \multirow[t]{2}{*}{ X-Rate } & -0.019 & $-0.097 * * *$ & -0.097 & 0.026 & -0.016 & -0.017 \\
\hline & $(1.04)$ & $(4.36)$ & $(0.86)$ & $(1.17)$ & $(0.80)$ & $(0.17)$ \\
\hline \multirow[t]{2}{*}{ Year } & $0.065 * * *$ & $0.096 * * *$ & 0.096 & $0.049 * * *$ & $0.077 * * *$ & 0.078 \\
\hline & $(10.45)$ & $(8.58)$ & $(0.61)$ & $(8.20)$ & $(7.61)$ & $(0.54)$ \\
\hline \multirow[t]{2}{*}{ Residuals } & & & $1.000 * * *$ & & & $1.000 * * *$ \\
\hline & & & $(69.53)$ & & & $(102.16)$ \\
\hline \multirow[t]{2}{*}{ Constant } & $-133.771 * * *$ & $-163.314^{* * *}$ & $-188.068^{* * *}$ & $-122.46^{* * *}$ & $-144.58 * * *$ & $-169.279 * * *$ \\
\hline & $(11.05)$ & $(9.71)$ & $(205.70)$ & $(10.84)$ & $(10.32)$ & (189.38) \\
\hline Observations & 769 & 769 & 769 & 665 & 665 & 665 \\
\hline R-squared & 0.64 & 0.79 & 0.79 & 0.82 & 0.89 & 0.89 \\
\hline
\end{tabular}

Robust t-statistics reported in parentheses. $* * *$ significant at $1 \%$ level. $* *$ significant at $5 \%$ level.

* significant at $10 \%$ level. 
Table 4: Bilateral Data without Differences (XTFEVD Estimates)

\begin{tabular}{|c|c|c|c|}
\hline & (1) & (2) & (3) \\
\hline & US Stock & US Sales & OECD \\
\hline \multirow[t]{2}{*}{ Parent GDP } & $1.473 * * *$ & $2.639 * * *$ & $2.197 * * *$ \\
\hline & $(8.16)$ & $(10.60)$ & $(12.10)$ \\
\hline \multirow[t]{2}{*}{ Parent Pop } & $-6.443 * * *$ & $-2.981 * * *$ & $-3.545 * * *$ \\
\hline & (12.28) & (3.89) & $(5.30)$ \\
\hline \multirow[t]{2}{*}{ Parent TC } & $-11.383 * * *$ & $-13.519 * * *$ & $8.693 * * *$ \\
\hline & $(7.53)$ & $(6.10)$ & $(5.35)$ \\
\hline \multirow[t]{2}{*}{ Host GDP } & $1.822 * * *$ & $2.309 * * *$ & $1.667^{* * *}$ \\
\hline & $(9.92)$ & $(9.19)$ & $(8.67)$ \\
\hline \multirow[t]{2}{*}{ Host Pop } & $-2.026^{* * *}$ & $-3.188^{* * *}$ & $-3.617 * * *$ \\
\hline & $(3.66)$ & $(4.08)$ & $(5.50)$ \\
\hline \multirow[t]{2}{*}{ Host TC } & $-2.539 *$ & $-6.911 * * *$ & 2.056 \\
\hline & $(1.69)$ & $(3.23)$ & $(1.28)$ \\
\hline \multirow[t]{2}{*}{ Host Inv Cost } & $-1.081 * * *$ & -0.587 & $-1.091 * * *$ \\
\hline & $(3.22)$ & $(1.23)$ & $(3.62)$ \\
\hline \multirow[t]{2}{*}{ Parent School } & $0.231 * * *$ & $0.626 * * *$ & 0.073 \\
\hline & $(5.20)$ & $(10.13)$ & $(1.34)$ \\
\hline \multirow[t]{2}{*}{ Host School } & $-0.269 * * *$ & $-0.195^{* * *}$ & 0.065 \\
\hline & $(6.24)$ & $(3.15)$ & $(1.25)$ \\
\hline \multirow[t]{2}{*}{ Parent PD } & $8.799^{* * *}$ & $3.745^{* * *}$ & $2.195 * * *$ \\
\hline & $(1.12 \mathrm{e}+13)$ & $(3.71 \mathrm{e}+12)$ & $(14854.13)$ \\
\hline \multirow[t]{2}{*}{ Host PD } & $3.089 * * *$ & $3.526 * * *$ & $4.345^{* * *}$ \\
\hline & $(3.93 e+12)$ & $(3.49 \mathrm{e}+12)$ & \begin{tabular}{|l|}
$(481.63)$ \\
\end{tabular} \\
\hline \multirow[t]{2}{*}{ Parent Independence } & $0.713 * * *$ & $-0.837 * * *$ & $0.991 * * *$ \\
\hline & (86.38) & $(66.25)$ & $(31.89)$ \\
\hline \multirow[t]{2}{*}{ Host Independence } & $-0.940 * * *$ & -0.059 & $-1.377 * * *$ \\
\hline & $(16.02)$ & $(0.78)$ & $(42.74)$ \\
\hline \multirow[t]{2}{*}{ Parent Masculinity } & $4.541 * * *$ & $1.610^{* * *}$ & $1.763^{* * *}$ \\
\hline & $(74.88)$ & (20.44) & $(46.37)$ \\
\hline \multirow[t]{2}{*}{ Host Masculinity } & $1.585^{* * *}$ & $1.874 * * *$ & $2.856 * * *$ \\
\hline & $(21.96)$ & (20.94) & $(73.31)$ \\
\hline \multirow{2}{*}{ Parent Uncertainty } & $-5.524 * * *$ & $-2.807 * * *$ & $-0.907 * * *$ \\
\hline & (82.67) & (32.18) & $(52.56)$ \\
\hline \multirow[t]{2}{*}{ Host Uncertainty } & $-3.322 * * *$ & $-2.348 * * *$ & $-2.943 * * *$ \\
\hline & $(83.03)$ & $(45.01)$ & $(167.23)$ \\
\hline \multirow[t]{2}{*}{ Parent Time } & $2.453 * * *$ & $1.256^{* * * *}$ & $3.324 * * *$ \\
\hline & $(62.67)$ & (24.82) & $(86.34)$ \\
\hline \multirow[t]{2}{*}{ Host Time } & $-0.506^{* * *}$ & -0.136 & $1.640 * * *$ \\
\hline & $(6.47)$ & $(1.35)$ & $(39.15)$ \\
\hline \multirow{2}{*}{ Parent Area } & $2.664 * * *$ & $0.440 * * *$ & $0.949 * * *$ \\
\hline & $(34.97)$ & $(4.45)$ & $(26.20)$ \\
\hline Host Area & -0.084 & $0.889^{* * *}$ & $1.128 * * *$ \\
\hline
\end{tabular}




\begin{tabular}{|c|c|c|c|}
\hline & $(1.34)$ & $(10.59)$ & (33.63) \\
\hline \multirow[t]{2}{*}{ Distance } & $-10.315 * * *$ & $-9.554 * * *$ & $-9.851 * * *$ \\
\hline & $(169.40)$ & $(121.75)$ & $(1117.40)$ \\
\hline \multirow{2}{*}{ Distance Sq. } & $0.713 * * *$ & $0.710 * * *$ & $0.581 * * *$ \\
\hline & $(44.21)$ & $(34.27)$ & $(64.75)$ \\
\hline \multirow[t]{2}{*}{ Colony } & $5.758 * * *$ & $1.537 * * *$ & $3.906 * * *$ \\
\hline & $(330.11)$ & $(70.44)$ & $(23.23)$ \\
\hline \multirow[t]{2}{*}{ Common Lang } & $-3.635 * * *$ & -0.376 & $-1.524 * * *$ \\
\hline & $(4.28)$ & $(0.36)$ & $(132.90)$ \\
\hline \multirow[t]{2}{*}{ Island } & $-2.389 * * *$ & $-2.590 * * *$ & $-3.472 * * *$ \\
\hline & $(42.35)$ & $(37.57)$ & $(55.13)$ \\
\hline \multirow[t]{2}{*}{ Landlock } & $-1.147 * * *$ & $-0.539 * * *$ & $-1.651 * * *$ \\
\hline & $(12.54)$ & $(4.58)$ & $(39.95)$ \\
\hline \multirow[t]{2}{*}{ Inbound } & 0.000 & 0.000 & $0.699 * * *$ \\
\hline & $(0.00)$ & $(0.00)$ & $(23.59)$ \\
\hline \multirow[t]{2}{*}{ X-rate } & -0.000 & -0.000 & 0.000 \\
\hline & $(0.00)$ & $(0.00)$ & $(0.01)$ \\
\hline \multirow[t]{2}{*}{ Year } & 0.051 & -0.081 & $0.064 * *$ \\
\hline & $(0.78)$ & $(0.96)$ & $(2.15)$ \\
\hline \multirow[t]{2}{*}{ Residuals } & $1.000 * * *$ & $1.000 * * *$ & $1.000 * * *$ \\
\hline & $(248.96)$ & $(87.24)$ & $(269.21)$ \\
\hline \multirow[t]{2}{*}{ Constant } & $-128.228 * * *$ & $91.091 * * *$ & $-187.852 * * *$ \\
\hline & $(37.21)$ & $(21.59)$ & $(236.82)$ \\
\hline Observations & 997 & 792 & 5450 \\
\hline R-squared & 0.96 & 0.96 & 0.94 \\
\hline
\end{tabular}

Robust t-statistics reported in parentheses. $* * *$ significant at $1 \%$ level. $* *$ significant at $5 \%$ level.

* significant at $10 \%$ level. 


\section{Data Appendix}

Table A1: Variable Definitions and Sources

\begin{tabular}{|c|c|c|}
\hline Variable Name & Description & Source \\
\hline Real FDI stock & $\ln$ (parent's FDI stock in millions of constant 2000 USD) & BEA \\
\hline Real FDI sales & $\ln$ (Total sales of foreign affiliates in millions of constant USD) & BEA \\
\hline Parent GDP & $\ln ($ parent county real GDP in millions of constant 2000 USD) & WDI \\
\hline Parent Pop & $\ln$ (parent country population in thousands) & WDI \\
\hline Parent TC & $\ln ($ GDP of parent/(Exports+Imports of parent)) & WDI \\
\hline Host GDP & $\ln ($ host county real GDP in millions of constant 2000 USD) & WDI \\
\hline Host Pop & $\ln$ (host country population in thousands) & WDI \\
\hline Host TC & $\ln ($ GDP of host/(Exports+Imports of host)) & WDI \\
\hline Host Inv Cost & $\ln (1 /$ host's BERI measure of business environment risk $)$ & BERI \\
\hline Colony & $=1$ if used to be in same colony group together & Rose (2004) \\
\hline Common Lang & $=1$ if common language & Rose (2004) \\
\hline Island & \# of island nations in pair & Rose (2004) \\
\hline Landlock & \# of landlocked nations in pair & Rose (2004) \\
\hline Distance & Ln of miles between capital cities & http://www.indo.com \\
\hline Distance Sq. & $(\text { Distance })^{2}$ & Our construction \\
\hline Parent Area & Ln of square kilometers of area of Parent & WDI \\
\hline Host Area & Ln of square kilometers of area of Host & WDI \\
\hline Inbound & $=1$ if inbound & Our construction \\
\hline X-rate & $\begin{array}{l}\% \text { change in the exchange rate between parent and host (or country and } \\
\text { US in WB data) from } t-1 \text { to } t \text {. }\end{array}$ & WDI \\
\hline Parent School & Parent country average years of schooling for those over age 25 & Barro \& Lee (2000) \\
\hline Host School & Host country average years of schooling for those over age 25 & Barro \& Lee (2000) \\
\hline School Diff Neg & - Ln of (Parent School - Host School) where parent has less schooling & Our construction \\
\hline School Diff Pos & Ln of (Parent School - Host School) where parent has more schooling & Our construction \\
\hline Cultural differences & Scores from 1 to 100 & \\
\hline Parent PD & $\begin{array}{l}\text { Parent country score on power distance } \\
\text { High values indicate acceptance of a less equal society }\end{array}$ & Hofstede (2001) \\
\hline Host PD & Host country score on power distance & Hofstede (2001) \\
\hline PD Diff Neg & Ln of abs value of (Parent PD - Host PD) where parent has lower PD & Our construction \\
\hline PD Diff Pos & Ln of abs value of (Parent PD - Host PD) where parent has higher PD & Our construction \\
\hline Parent Individualism & $\begin{array}{l}\text { Parent country score on individualism } \\
\text { High values for more individualistic societies }\end{array}$ & Hofstede (2001) \\
\hline Host Individualism & Host country score on individualism & Hofstede (2001) \\
\hline $\begin{array}{l}\text { Individualism Diff } \\
\text { Neg }\end{array}$ & $\begin{array}{l}\text { Ln of abs value of (Parent Individualism - Host Individualism) where } \\
\text { parent has lower Individualism }\end{array}$ & Our construction \\
\hline $\begin{array}{l}\text { Individualism Diff } \\
\text { Pos }\end{array}$ & $\begin{array}{l}\text { Ln of abs value of (Parent Individualism - Host Individualism) where } \\
\text { parent has higher Individualism }\end{array}$ & Our construction \\
\hline Parent Masculinity & $\begin{array}{l}\text { Parent country score on masculinity } \\
\text { High values for countries with "masculine" values. }\end{array}$ & Hofstede (2001) \\
\hline Host Masculinity & Host country score on masculinity & Hofstede (2001) \\
\hline Masculinity Diff Neg & $\begin{array}{l}\text { Ln of abs value of (Parent Masculinity - Host Masculinity) where } \\
\text { parent has lower scores }\end{array}$ & Our construction \\
\hline Masculinity Diff Pos & $\begin{array}{l}\text { Ln of abs value of (Parent Masculinity - Host Masculinity) where } \\
\text { parent has higher scores }\end{array}$ & Our construction \\
\hline Parent Uncertainty & $\begin{array}{l}\text { Parent country score on uncertainty tolerance } \\
\text { High values for countries where individuals value predictability and }\end{array}$ & Hofstede (2001) \\
\hline
\end{tabular}




\begin{tabular}{|l|l|l|}
\hline & avoid uncertain situations & \\
\hline Host Uncertainty & Host country score on uncertainty tolerance & Hofstede (2001) \\
\hline Uncertainty Diff Neg & $\begin{array}{l}\text { Ln of abs value of (Parent Uncertainty - Host Uncertainty) where } \\
\text { parent has lower scores }\end{array}$ & Our construction \\
\hline Uncertainty Diff Pos & $\begin{array}{l}\text { Ln of abs value of (Parent Uncertainty - Host Uncertainty) where } \\
\text { parent has higher scores }\end{array}$ & Our construction \\
\hline Parent Time & $\begin{array}{l}\text { Parent country score on long-term orientation } \\
\text { High values in countries where people are oriented toward future and } \\
\text { value thrift and perseverance }\end{array}$ & Hofstede (2001) \\
\hline Host Time & Host country score on long-term orientation & Hofstede (2001) \\
\hline Time Diff Neg & $\begin{array}{l}\text { Ln of abs value of (Parent Time - Host Time) where parent has lower } \\
\text { scores }\end{array}$ & Our construction \\
\hline Time Diff Pos & $\begin{array}{l}\text { Ln of abs value of (Parent Time - Host Time) where parent has higher } \\
\text { scores }\end{array}$ & Our construction \\
\hline
\end{tabular}

BEA= Bureau of Economic Analysis; www.bea.doc.gov/bea/di/dilfdibal.htm

WDI $=$ World Development Indicators; http://publications.worldbank.org/WDI/

BERI $=$ Business Environment Risk Intelligence; www.beri.com 


\section{Tables A2: Summary Statistics}

\section{A2.1 US data}

\begin{tabular}{|c|c|c|c|c|c|c|c|c|}
\hline \multirow[b]{2}{*}{ Variable } & \multicolumn{4}{|c|}{ FDI stock (1038 observations) } & \multicolumn{4}{|c|}{ FDI sales ( 816 observations) } \\
\hline & Mean & Std. Dev. & Min & Max & Mean & Std.Dev. & Min & Max \\
\hline FDI stock/sales & 8.05 & 2.38 & 1.31 & 12.53 & 9.33 & 2.51 & 0.02 & 13.17 \\
\hline Parent GDP & 27.92 & 1.90 & 24.02 & 29.91 & 27.97 & 1.88 & 23.71 & 29.91 \\
\hline Parent Pop & 11.31 & 1.57 & 8.04 & 14.05 & 11.34 & 1.56 & 8.09 & 14.04 \\
\hline Parent TC & 0.29 & 0.05 & 0.19 & 0.40 & 0.29 & 0.05 & 0.20 & 0.40 \\
\hline Host GDP & 27.89 & 1.86 & 24.02 & 29.91 & 27.92 & 1.86 & 24.23 & 29.91 \\
\hline Host Pop & 11.34 & 1.52 & 8.13 & 14.05 & 11.34 & 1.53 & 8.16 & 14.05 \\
\hline Host TC & 0.29 & 0.05 & 0.19 & 0.40 & 0.29 & 0.05 & 0.19 & 0.40 \\
\hline Host Inv Cost & -4.15 & 0.19 & -4.42 & -3.51 & -4.14 & 0.18 & -4.42 & -3.56 \\
\hline School Diff Neg & 0.56 & 0.75 & -1.27 & 2.32 & 0.55 & 0.74 & -1.27 & 2.29 \\
\hline School Diff Pos & 0.64 & 0.77 & -1.02 & 2.32 & 0.63 & 0.76 & -1.02 & 2.30 \\
\hline PD Diff Neg & -1.34 & 1.43 & -3.99 & 0.00 & -1.32 & 1.44 & -3.99 & 0.00 \\
\hline PD Diff Pos & 1.15 & 1.39 & 0.00 & 3.99 & 1.18 & 1.40 & 0.00 & 4.16 \\
\hline $\begin{array}{l}\text { Independence } \\
\text { Diff Neg }\end{array}$ & -1.49 & 1.67 & -4.34 & 0.00 & -1.49 & 1.68 & -4.34 & 0.00 \\
\hline $\begin{array}{l}\text { Independence } \\
\text { Diff Pos }\end{array}$ & 1.59 & 1.73 & 0.00 & 4.34 & 1.61 & 1.73 & 0.00 & 4.34 \\
\hline $\begin{array}{l}\text { Masculinity Diff } \\
\text { Neg }\end{array}$ & -1.18 & 1.43 & -4.04 & 0.00 & -1.18 & 1.43 & -4.04 & 0.00 \\
\hline $\begin{array}{l}\text { Masculinity Diff } \\
\text { Pos }\end{array}$ & 1.27 & 1.46 & 0.00 & 4.04 & 1.26 & 1.46 & 0.00 & 4.04 \\
\hline $\begin{array}{l}\text { Uncertainity Diff } \\
\text { Neg }\end{array}$ & -1.41 & 1.55 & -4.06 & 0.00 & -1.41 & 1.55 & -4.06 & 0.00 \\
\hline $\begin{array}{l}\text { Uncertainity Diff } \\
\text { Pos }\end{array}$ & 1.30 & 1.50 & 0.00 & 4.06 & 1.33 & 1.52 & 0.00 & 4.06 \\
\hline Time Diff Neg & -1.15 & 1.39 & -4.49 & 0.00 & -1.15 & 1.40 & -4.49 & 0.00 \\
\hline Time Diff Pos & 1.10 & 1.35 & 0.00 & 4.49 & 1.10 & 1.37 & 0.00 & 4.49 \\
\hline Parent Area & 14.40 & 2.03 & 10.40 & 16.05 & 14.39 & 2.04 & 10.40 & 16.05 \\
\hline Host Area & 14.36 & 2.06 & 10.40 & 16.05 & 14.36 & 2.06 & 10.40 & 16.05 \\
\hline Distance & 8.40 & 0.56 & 6.12 & 9.20 & 8.39 & 0.56 & 6.12 & 9.20 \\
\hline Distance Sq. & 70.79 & 8.68 & 37.46 & 84.66 & 70.78 & 8.68 & 37.46 & 84.66 \\
\hline Colony & 0.04 & 0.20 & 0 & 1 & 0.04 & 0.20 & 0 & 1 \\
\hline Common Lang & 0.26 & 0.44 & 0 & 1 & 0.26 & 0.44 & 0 & 1 \\
\hline Island & 0.14 & 0.35 & 0 & 1 & 0.14 & 0.35 & 0 & 1 \\
\hline Landlock & 0.11 & 0.32 & 0 & 1 & 0.11 & 0.32 & 0 & 1 \\
\hline Inbound & 0.49 & 0.50 & 0 & 1 & 0.49 & 0.50 & 0 & 1 \\
\hline X-rate & $1.00 \mathrm{E}+08$ & $1.92 \mathrm{E}+09$ & -0.99952 & $5.21 \mathrm{E}+10$ & 8550915 & $1.75 E+08$ & -0.99952 & $4.80 \mathrm{E}+09$ \\
\hline Year & 1990 & 6.06 & 1980 & 2000 & 1991 & 4.83 & 1983 & 2000 \\
\hline
\end{tabular}




\section{A2.2 OECD data (5450 Observations)}

\begin{tabular}{|l|l|l|l|l|}
\hline Variable & Mean & Std.Dev. & Min & Max \\
\hline FDI stock & 5.80 & 3.00 & -2.30 & 11.96 \\
\hline Parent GDP & 26.75 & 1.37 & 23.49 & 29.87 \\
\hline Parent Pop & 10.18 & 1.41 & 8.08 & 14.05 \\
\hline Parent TC & 0.25 & 0.04 & 0.19 & 0.40 \\
\hline Host GDP & 26.73 & 1.33 & 24.28 & 29.87 \\
\hline Host Pop & 10.25 & 1.42 & 8.16 & 14.05 \\
\hline Host TC & 0.25 & 0.04 & 0.19 & 0.40 \\
\hline Host Inv Cost & -4.11 & 0.17 & -4.42 & -3.60 \\
\hline School Diff Neg & 0.13 & 0.76 & -6.21 & 2.16 \\
\hline School Diff Pos & 0.19 & 0.82 & -6.21 & 2.16 \\
\hline PD Diff Neg & -1.31 & 1.46 & -4.23 & 0.00 \\
\hline PD Diff Pos & 1.21 & 1.46 & 0.00 & 4.53 \\
\hline Independence Diff Neg & -1.33 & 1.50 & -4.29 & 0.00 \\
\hline Independence Diff Pos & 1.26 & 1.49 & 0.00 & 4.29 \\
\hline Masculinity Diff Neg & -1.51 & 1.65 & -4.50 & 0.00 \\
\hline Masculinity Diff Pos & 1.43 & 1.64 & 0.00 & 4.62 \\
\hline Uncertainity Diff Pos & -1.49 & 1.61 & -4.39 & 0.00 \\
\hline Uncertainity Diff Pos & 1.41 & 1.58 & 0.00 & 4.39 \\
\hline Time Diff Neg & -1.13 & 1.42 & -4.65 & 0.00 \\
\hline Time Diff Pos & 1.23 & 1.46 & 0.00 & 4.65 \\
\hline Parent Area & 12.73 & 1.71 & 10.40 & 16.05 \\
\hline Host Area & 12.81 & 1.75 & 10.40 & 16.05 \\
\hline Distance & 7.50 & 1.13 & 4.76 & 9.42 \\
\hline Distance Sq. & 57.47 & 16.71 & 22.70 & 88.64 \\
\hline Colony & 0.04 & 0.20 & 0 & 1 \\
\hline Common Lang & 0.12 & 0.32 & 0 & 1 \\
\hline Island & 0.20 & 0.42 & 0 & 2 \\
\hline Landlock & 0.29 & 0.50 & 0 & 2 \\
\hline X-rate & 3.29 & 85.65 & -1.00 & 3985.28 \\
\hline Year & 1994 & 4.58 & 1983 & 2000 \\
\hline Inward & 0.72 & 0.45 & 0 & 1 \\
\hline & & & & \\
\hline
\end{tabular}




\section{A2.3 World Bank data}

\begin{tabular}{|l|l|l|l|l|l|l|l|l|}
\hline & \multicolumn{3}{|l|}{ Inbound (769 observations) } & \multicolumn{3}{l|}{ Outbound (665 observations) } \\
\cline { 2 - 11 } Variable & Mean & Std.Dev. & Min & Max & Mean & Std.Dev. & Min & Max \\
\hline $\begin{array}{l}\text { FDI } \\
\text { inflow/outflow }\end{array}$ & 21.27 & 2.03 & 12.45 & 26.50 & 21.30 & 2.34 & 11.02 & 26.23 \\
\hline GDP host/parent & 26.15 & 1.37 & 23.49 & 29.91 & 26.39 & 1.31 & 23.49 & 29.91 \\
\hline POP host/parent & 10.28 & 1.50 & 7.97 & 14.05 & 10.17 & 1.43 & 7.97 & 14.05 \\
\hline TC host/parent & 0.26 & 0.05 & 0.19 & 0.48 & 0.26 & 0.04 & 0.19 & 0.42 \\
\hline $\begin{array}{l}\text { School } \\
\text { host/parent }\end{array}$ & 1.97 & 0.43 & 0.25 & 2.51 & 2.06 & 0.33 & 0.86 & 2.51 \\
\hline PD host/parent & 3.78 & 0.49 & 2.40 & 4.64 & 3.72 & 0.48 & 2.40 & 4.64 \\
\hline $\begin{array}{l}\text { Independence } \\
\text { host/parent }\end{array}$ & 4.00 & 0.49 & 2.89 & 4.51 & 4.06 & 0.46 & 2.89 & 4.51 \\
\hline $\begin{array}{l}\text { Masculinity } \\
\text { host/parent }\end{array}$ & 3.78 & 0.69 & 1.61 & 4.70 & 3.72 & 0.74 & 1.61 & 4.70 \\
\hline $\begin{array}{l}\text { Uncertainty } \\
\text { host/parent }\end{array}$ & 4.03 & 0.38 & 3.14 & 4.64 & 4.05 & 0.39 & 3.14 & 4.64 \\
\hline Time host/parent & 3.64 & 0.41 & 2.56 & 4.77 & 3.63 & 0.41 & 2.56 & 4.77 \\
\hline Area host/parent & 12.88 & 1.79 & 10.40 & 16.05 & 12.87 & 1.81 & 10.40 & 16.05 \\
\hline Island host/parent & 0.21 & 0.41 & 0 & 1 & 0.19 & 0.39 & 0 & 1 \\
\hline $\begin{array}{l}\text { Landlockock } \\
\text { host/parent }\end{array}$ & 0.10 & 0.31 & 0 & 1 & 0.11 & 0.31 & 0 & 1 \\
\hline $\begin{array}{l}\text { X-rate } \\
\text { host/parent }\end{array}$ & 0.17 & 1.42 & -1.00 & 23.10 & 0.17 & 1.51 & -1.00 & 23.10 \\
\hline Year & 1987 & 8.45 & 1970 & 2000 & 1987.423 & 8.363 & 1970 & 2000 \\
\hline
\end{tabular}


Table A3: Countries in Sample

\begin{tabular}{|l|l|l|}
\hline US data & OECD data & World Bank Data \\
\hline Australia & Australia & Australia \\
\hline Austria & Austria & Austria \\
\hline Belgium & & Bangladesh \\
\hline Brazil & Belgium & Belgium \\
\hline Canada & Canada & Brazil \\
\hline China & China & Canada \\
\hline Czech Republic & Czech Republic & China \\
\hline Denmark & Denmark & Czech Republic \\
\hline Finland & Finland & Denmark \\
\hline France & France & Finland \\
\hline Germany & Germany & France \\
\hline Hungary & Hungary & Germany \\
\hline India & India & Hungary \\
\hline Ireland & Ireland & India \\
\hline Italy & Italy & Ireland \\
\hline Japan & Japan & Italy \\
\hline Korea (South) & Korea (South) & Japan \\
\hline Netherlands & Netherlands & Korea (South) \\
\hline New Zealand & New Zealand & Netherlands \\
\hline Norway & Norway & New Zealand \\
\hline Pakistan & & Norway \\
\hline Philippines & & \\
\hline Poland & Poland & Philippines \\
\hline Portugal & Portugal & Poland \\
\hline Slovak Republic & Slovak Republic & \\
\hline Spain & Spain & Portugal \\
\hline Sweden & Swevak Republic \\
\hline Switzerland & Switzerland & Spain \\
\hline & & Sweden \\
\hline United Kingdom & United Kingdom & Switzerland \\
\hline United States & United States & Thailand \\
\hline a only in sales data & b parent country only & United Kingdom \\
\hline & & \\
\hline
\end{tabular}

